\title{
O Movimento de Constituição dos Dados no Proceder Fenomenológico em Pesquisas no Âmbito da Formação de Professores que Ensinam Matemática \\ The Movement of Constitution of the Data in the Phenomenological Procedure in Researches in the Scope of the Teacher Education that Teach Mathematics
}

\author{
Nelem Orlowskiab; Marcelo Lambach ${ }^{\text {b }}$ Luciane Ferreira Mocrosky*b

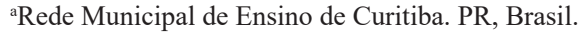 \\ bUniversidade Tecnológica Federal do Paraná, Programa de Pós-Graduação Stricto Sensu em Formação Científica, Educacional e Tecnológica. PR, \\ Brasil. \\ *E-mail: mocrosky@utfpr.edu.br.
}

\begin{abstract}
Resumo
Neste texto apresentamos aspectos do modo de proceder fenomenológico no âmbito das pesquisas de formação de professores que ensinam matemática e sua relevância para a região de inquérito da educação matemática, guiados pela interrogação: Como o proceder filosóficofenomenológico, em pesquisas na formação de professores que ensinam matemática, pode contribuir para o professor que ensina matemática (PEM) como campo de estudo?. Para isso, explicitamos algumas compreensões epistemológicas sobre a corrente fenomenológica num percurso histórico-filosófico, tematizando o modo como também orienta uma postura metodológica que, no campo das pesquisas em formação de professores, reforça a importância das investigações considerarem a pessoa em sua integralidade, neste caso, o professor em sua condição de formar-se. Expomos uma breve revisita às pesquisas sobre a formação de professores, articulando-as aos modos de proceder fenomenológicos. Especificamente, destacamos como se dá o movimento de constituição dos dados, dialogando com suas possibilidades no pesquisar qualitativo, tendo em vista a responsabilidade e o envolvimento com os modos de formar-se professor de cada um que se lança na profissão e assim vai se entendendo professor. Concluímos o texto sinalizando como tais modos possibilitam aos pesquisadores formarem-se com seus pares num movimento contínuo e constitutivo de docência, orientado pelo cuidado que se desdobra na escuta atenta do outro, tendo em vista a condição de conhecer e produzir conhecimento de um modo coletivo e dialógico, em perspectiva e provisório.
\end{abstract}

Palavras-chave: Formação de Professores. Educação Matemática. Fenomenologia.

\begin{abstract}
In this text we present aspects of the phenomenological way of proceeding in the context of teacher education researches that teach mathematics and its relevance to the Mathematical Education survey region, guided by the question: How does the philosophical-phenomenological procedure, in research in teacher education who teach mathematics, can contribute to the teacher who teaches mathematics (PEM) as a field of study? For this, we explain some epistemological comprehensions about the phenomenological current in a historical-philosophical path, focusing on the way in which it also guides a methodological stance, which in the context of research in teacher education, reinforces the importance of investigations to consider the person in their entirety, in this case, the teacher in his condition to graduate. We expose a brief revisit to the research on teacher education, articulating them to the phenomenological ways of proceeding, specifically we highlight how the movement of constitution of the data occurs, dialoguing with its possibilities in qualitative research, in view of the responsibility and involvement with the ways of becoming a teacher for each one who launches into the profession and thus becomes a teacher. We conclude the text by signaling how such modes enable researchers to form with their peers in a continuous and constitutive movement of teaching, guided by the care that unfolds in the attentive listening of the other, in view of the condition of understanding and producing knowledge in a collective way and dialogical, in perspective and provisional.
\end{abstract}

Keywords: Teacher Education. Mathematical Education. Phenomenology.

\section{Introdução}

Nos estudos encaminhados no Grupo de Estudos e Pesquisa Grupo de Estudos e Pesquisa em Formação de Professores (GEForProf/UTFPR), temos interrogado a formação de professores que ensinam matemática, na região de inquérito da educação matemática. Neste texto, buscamos problematizar o formar formando-se como fio condutor de compreensões-intepretações, tendo em vista o modo de proceder fenomenológico em pesquisas no referido âmbito.

Das perguntas recorrentes no movimento formativo dos membros do grupo de estudo, destacam-se: Qual a relevância investigativa de se optar por um proceder metodológico fundamentado em uma abordagem fenomenológica em pesquisas? Como o proceder filosófico-fenomenológico em pesquisas na formação de professores que ensinam matemática pode contribuir para "O Professor que Ensina Matemática (PEM) como campo de estudo" (Fiorentini, Passos, \& Lima, 2016) enquanto tendência que vem despontando fortemente no âmbito das pesquisas na educação matemática?

Com essas perguntas de fundo, muitos aspectos deste proceder metodológico poderiam ser abordados e, pela impossibilidade de apresentá-los com o devido cuidado e profundidade em um artigo, optamos em explicitar apenas um: o movimento de constituição dos dados no proceder 
fenomenológico em pesquisas no âmbito da formação de professores que ensinam matemática.

Para tanto, organizamos o texto em quatro partes: na primeira, expomos algumas compreensões epistemológicas sobre a corrente filosófica fenomenológica. Na segunda, revisitamos pesquisas que tematizam a formação de professores, articulando-as aos modos de proceder fenomenológicos, explicitados na terceira parte. Concluímos o artigo sinalizando como tais modos possibilitam aos pesquisadores formarem-se com seus pares, num movimento contínuo e constitutivo de formação, orientados pelo cuidado imprescindível de escuta atenta do outro.

\section{Compreensões Epistemológicas: Por Que Fenomenologia?}

No percurso dos modos humanos de conhecer, segundo Cupani (2009), o interesse filosófico pela ciência modificouse no século XVII com o surgimento da ciência experimental moderna, que tinha um modo de questionar a natureza diferente das ciências filosóficas, que buscavam compreendêla. Destacamos a virada fundamental ocorrida com René Descartes, que fundou as bases da atitude racionalista analítica da ciência moderna, enraizando a importância das matemáticas na ciência natural, e, de outra perspectiva, inaugurando uma separação sistemática entre a consciência e a realidade. Determinando o domínio do racionalismo como modo de conhecer o mundo e a realidade no fazer científico de modo inexorável, "somente as pesquisas matemáticoexperimentais mereciam ser reconhecidas como 'ciência', como autêntico saber" (Cupani, 2009, p. 22).

No âmbito da ciência e do conhecimento humano, numa perspectiva histórico-filosófica de investigação, trilharse-iam caminhos cada vez mais acentuados e vincados na cristalização da antinomia sujeito e objeto. A realidade seria posta como uma representação e o sujeito como res cogitans, uma 'coisa pensante'.

Ainda no século XVII, Descartes solidificou um pensar científico e filosófico, ancorado na tese de que o conhecimento produzido anteriormente à era moderna não se prestava à ciência. Entendeu ser preciso mais rigor nos métodos para legitimar as descobertas, utilizando-se de processo analítico que tornasse preciso o que está na mente (res-cogitans) e na matéria (res-extensa) (Mocrosky \& Bicudo, 2013, p.409).

Legitimou-se a matematização como exigência incondicional de rigor. Ao ter-se a matemática como sentido orientador do modo como se explica e entende-se a realidade, o único critério de validação da verdade torna-se a objetividade, ou seja, "existe uma objetividade da razão que possibilita produzir conhecimento, quantificando a realidade e promovendo a universalidade do conhecido" (Mocrosky \& Bicudo, 2013, p.409). Destarte, o conhecimento, para ser considerado válido, necessariamente deveria ser o objetivo, uma vez que este se sustenta pela sua mensurabilidade.

As relações matemáticas ampliam as possibilidades advindas da experiência direta e generalizam estruturas presentes. Neste contexto, a concretização de um conhecimento se dá pela ordenação das coisas que institui regras, pela funcionalidade dessas regras ordenadas, chegando a padronizações que permitem generalizações, independentes do alcance sensitivo. Nesse sentido, se constituiu a lógica (moderna) (Mocrosky \& Bicudo, 2013, p.410).

Este modo de pensar o mundo, a ciência e o conhecimento tiveram como uma de suas consequências o cientificismo. Com ele, os modos de investigar foram cada vez mais se distanciando do mundo vivido. Segundo Husserl (2012), a ciência sofre um afastamento do seu sentido na existência humana e os objetos, por sua vez, apresentam-se como representações do sujeito que constitui a realidade, denunciando uma ruptura entre a consciência de si e de algo fora de si.

Nesse contexto, a fenomenologia surge também com a preocupação de superar a fragmentação entre sujeito e objeto ao se apresentar como uma filosofia e um método, que por seu fundador, Edmund Husserl (1859 - 1938), propõe “ir às coisas, elas mesmas" (Bicudo, 2020, p.33). A palavra 'fenomenologia' etimologicamente revela que é composta por 'fenômeno' mais 'logo', e significa “o que se mostra no ato de perceber ou de intuir. É correlato a quem percebe ou intui. Este que percebe ou intui realiza esses atos de acordo com suas especificidades" (Bicudo, 2020, p.35).

Fenomenologia pode ser entendida como uma corrente filosófica, um modo de compreender o mundo e as pessoas. No âmbito das pesquisas, também orienta uma postura metodológica de modos de proceder sistematicamente em que

[...] não se trata de expor o modus operandi de realizar pesquisa, mas sim de pensar de modo sistemático a respeito dos procedimentos de investigação, questionando-se sobre compreensões de mundo que tais procedimentos trazem consigo (Bicudo \& Miarka, 2015, p. 431).

Em tal filosofia e modos de proceder, não se pretende negar a ocupação da ciência com as próprias coisas. O proposto é uma volta às experiências vividas sem representações prévias, pois

[...] o investigador da natureza não se dá conta de que o fundamento permanente de seu trabalho mental, subjetivo é o mundo circundante (Lebenswelt) vital que constantemente é pressuposto como base, como terreno da atividade sobre o qual suas perguntas e seus métodos de pensar adquirem um sentido (Husserl, 2002, p. 90).

Assim, considera-se que não há possibilidade de conhecimento senão no/com o mundo entre as pessoas, sociedade e cultura em que se vivencia a experiência humana e o que ela pode significar a cada uma das pessoas. Não se busca estabelecer relações entre sujeito que conhece e objeto a ser conhecido como representação; a intencionalidade passa a ser o modo como acontece o enlace do par perceber e percebido (Batista, Mocrosky \& Mondini, 2017).

Desse modo, a noção de experiência se amplia, e não se trata mais somente de uma manipulação empírica ou experimento, mas um movimento de experienciar de si e do/no mundo, do 
significado do vivido. A pessoa experiencia não somente as coisas e o mundo, mas a si mesmo. Esse experienciar pessoal impregna-se de sentido, ou ainda, "não se trata de explicitar a constituição do mundo, mas tão somente do conhecimento que nós, seres humanos, produzimos ao habitá-lo" (Bicudo, 2020, p.31).

Entendendo e propondo tal modo de compreender o mundo, a pessoa, a realidade e o conhecimento, concordamos com Mondini, Mocrosky \& Paulo (2018, p.3) quando se referem à fenomenologia como uma alternativa para investigar as pessoas em sua plenitude, uma vez que "os métodos existentes até então, pautados nas ciências exatas, não davam conta de considerar o ser humano em sua totalidade".

Ao nos propormos a assumir uma postura fenomenológica no âmbito das pesquisas em formação de professores, estamos reforçando a importância de que as investigações considerem a pessoa em sua integralidade, neste caso, o professor em sua condição de formar-se para formar o outro. Eis por que fenomenologia - compreende-se que há outras posições epistêmicas e metodológicas que também têm propósitos similares.

$\mathrm{Na}$ sequência, explicitaremos o movimento de constituição dos dados no proceder fenomenológico, no âmbito das pesquisas de formação de professores que ensinam matemática.

\section{A Formação de Professores que Ensinam Matemática}

A formação continuada foi indicada pela LDB 9394/96 como responsabilidade legal das redes de ensino brasileiras. À época, era adjetivada como "capacitação em serviço" e tinha como objetivo a profissionalização docente, associando a ideia de continuidade à "formação em serviço" com o sentido de complemento para os professores atuantes (Gatti, 2008, p.60). Tal complemento evidencia, já de início, a fragilidade profissional, pois nem sempre foi possível tampouco ainda o é - aos professores compreenderem-se em formação, movimentando seu desenvolvimento profissional. Entendemos que este processo permanece ao longo de toda a carreira no magistério e requer um sentido profissional comum, no qual se intenciona constituir tempos e espaços de reflexão crítica na prática, um movimento de 'dentro para fora' (Ponte, 2002, 2012).

No entanto, os percursos da formação continuada de professores não se mostram transitáveis apenas por roteiros, modelos ou leis. Mostram-se, também, no/pelo próprio formar-se. Neste sentido, podemos vislumbrar nuances de um movimento histórico em que vão se revelando as intencionalidades formativas em pesquisas nos últimos anos, como o exposto por Imbérnon (2010, p.23), quando apresenta etapas de uma "imprecisa genealogia de conhecimento e sua relação com a formação", evidenciando o discurso predominante a cada uma delas.

Para o autor, nos anos de 1980 a nuance a que chamou de 'Metáfora do produto', compreendia que o conhecimento para formar professores se revelava como informações científicas, culturais e psicopedagógicas para transmissão, ou seja, uma formação como produto assimilável individualmente por meio de cursos. Já nos anos de 1990, despontava o desenvolvimento de habilidades profissionais para mudar as salas de aula, estratégias para reformular interpretações e esquemas pessoais dos professores em forma de oficinas e seminários: a 'Metáfora do processo'. Uma terceira etapa se deu nos 2000 com a 'Metáfora da construção', que constituiu o compartilhamento de significados no contexto educacional para mudanças nas instituições escolares, processo de práticas reflexivas e redes de formação presenciais e virtuais.

Há ainda mais uma fase que denomina "desejável", a "Metáfora da subjetividade, da intersubjetividade, do dialogismo", apontando para a construção coletiva com vistas à mudança no que chama de realidade educativa. Isso se daria, segundo ele, no bojo da elaboração e prática de projetos de intervenção nas comunidades envolvidas com educação, no qual as pesquisas incidem na prática ou, ainda, na participação da comunidade, com vistas à transformação (Imbernón, 2010, p.24).

O autor nos mostra alteração no sentido orientador da formação continuada e afirma que, nas últimas três décadas, o modo de se fazer presença da formação continuada revela uma herança em acontecimento de mudanças considerada por ele como significativas, tais como a crítica à racionalidade técnico-formadora. Os modelos de formação passaram a ser analisados, havendo a aproximação da formação continuada na escola, a necessidade da pesquisa e da reflexão da prática e uma maior teorização sobre a questão.

Em relação às mudanças, as pesquisas no âmbito da educação matemática revelam a composição de grupos colaborativos como "comunidades investigativas" (Fiorentini, 2016; Fiorentini \& Oliveira, 2013) e "trabalho coletivo/ colaborativo", (Nacarato, 2005; Nacarato \& Grando, 2015).

Ainda, nessa perspectiva de voltar-se ao professor, há grupos de pesquisa que se debruçam sobre a profissionalização docente em serviço. Nesse sentido, Ponte (2012), tem pesquisado o que chama de desenvolvimento profissional do professor, a profissionalização docente pela formação, propondo que o professor constrói seu 'conhecimento profissional' e que ele é diferente do conhecimento acadêmico de formadores e educadores matemáticos.

No cenário delineado pela breve reunião de entendimentos que povoam a educação matemática, percebemos um deslocamento nos modos de pensar as pesquisas na formação continuada: modelos de formação de professores para o esforço, a responsabilidade e o envolvimento com os modos de formar-se professor que cada um tem ao se lançar na profissão e nela ir se entendendo. O conhecimento da profissão pelo professor se mostra em processos constitutivos, em que o conhecimento científico, neste lócus de pesquisa, pode ser interpretado como coletivo e dialógico, em perspectivas e provisório, haja vista que a forma de ser professor está para a 
ação formativa sempre em vias de ser, de se dar.

No entanto, André (2011, p.30), em sua metanálise de pesquisas acadêmicas relacionadas à formação de professores até o ano de 2007, afere que, se por um lado houve um crescimento das pesquisas, por outro, o campo da formação de professores continua a ser "um conhecimento parcelado, incompleto". Destaca que muitas pesquisas do seu corpus de estudo apresentam fragilidades, principalmente no que diz respeito à descrição dos procedimentos metodológicos.

É no movimento de constituição dos dados que explicitamos, na sequência, como as pesquisas na abordagem fenomenológica podem possibilitar aberturas às investigações acadêmicas acerca da formação continuada de professores. Consideramo-la como mais uma possibilidade metodológica que poderá contribuir para campo de investigação da formação de professores.

\section{Movimento de Constituição dos Dados em Pesquisas com Abordagem Fenomenológica}

No âmbito da decisão metodológica, a abordagem fenomenológica solicita o pesquisar qualitativo, não apenas porque não trata do quantitativo em termos estatísticos, mas porque se vale de vivências (Bicudo, 2020). O que a distingue de uma pesquisa quantitativa também é solicitado pelos modos como se compreende o mundo como mundo-vida ${ }^{1}$, o solo histórico-cultural e social da existência humana em que não há a possibilidade de apartar 'pesquisador' e 'objeto de pesquisa'.

Neste modo de compreender, considera-se que o conhecimento não é apenas o que é produzido pelo pesquisador, mas por todos os indivíduos envolvidos intersubjetivamente em um processo dialógico de produção de saberes, tendo em vista as possibilidades de alteração de experiências culturais, históricas e sociais, bem como o modo de compreendê-las, interpretá-las e compreender-se com elas.

Por esse caminho é possível considerar os fundamentos e o fazer científico, a pedagogia e a educação como campos científicos em que há a possibilidade de uma "pedagogia fenomenológica" (Bicudo, 2010). Nela, o sujeito se lança intencionalmente às suas vivências e intersubjetivamente na constituição do conhecimento. Isto porque entende-se que o "ambiente da educação é subjetivo e também intersubjetivo e objetivo, como todo solo do mundo-vida em que habitamos" (Bicudo, 2020, p.52).

Assumir uma postura fenomenológica é realizar um trabalho sempre intencional, em que o educador se dá conta do que está ocorrendo consigo mesmo, com o mundo-vida escolar, com o aluno, visto como pessoa e como estando com os outros, seus companheiros de aula, com o tema que está sendo trabalhado, no contexto da região de inquérito em destaque, com o professor e com seu entorno. A dinâmica em ação é aquela do cuidado com a área de inquérito trabalhada e com a constituição da subjetividade/intersubjetividade de aluno-alunos-professor-conteúdo (Bicudo, 2010, p. 44-45).

Do exposto, vislumbramos a possibilidade de um 'objeto de pesquisa' como um fenômeno percebido, ou seja, ao visar à consciência que se volta para ele, num movimento intencional, temos a possibilidade de nos expressar para além da representação. Nessa direção, investigar a formação de professores solicita que o olhar se volte para o que compreendem pesquisado e pesquisador e como expressam suas compreensões.

$\mathrm{Na}$ pesquisa de abordagem fenomenológica não se apresenta uma resposta em termos de uma definição, mas explicitam-se compreensões do fenômeno, consoantes ao movimento interrogativo empreendido pelo pesquisador, que deságua na análise de uma descrição de situações em que ele se deu e como se deu. Também não há o abandono da literatura da área. Os estudos existentes no tema em foco se abrem ao diálogo entre texto, autor, sujeitos significativos da pesquisa e pesquisador, sempre no horizonte da interrogação orientadora da pesquisa, formulada inicialmente de modo a alavancar o estudo. Esta, por sua vez, guiará a pesquisa.

Elabora-se a interrogação abarcando dimensões de interesse do interrogado, segundo questões antecipadas das experiências vividas de quem está perguntando com a disposição e disponibilidade para percorrer caminhos que conduzam à compreensão sobre o estudado. $\mathrm{Na}$ pesquisa fenomenológica, os caminhos seguidos não são determinados previamente, mas, com a interrogação, eles vão se delineando. Não há um pesquisador e uma interrogação que se encontrem em meio a um trajeto. Pesquisador-interrogaçãoprocedimentos são inseparáveis, e o que acompanha essa relação indissolúvel conserva o mesmo caráter por estarem intrinsecamente ligados e comprometidos com o fenômeno interrogado (Mocrosky, 2015, p.147-148).

O que está no núcleo de um modo de proceder fenomenológico se assenta na descrição da vivência de um sujeito, que se dá conta das coisas sempre junto com os outros. Tem-se um modo de descrever que não toma o outro como um 'objeto' dado em sua objetividade e o compara. Antes, o pesquisador tem o cuidado e a responsabilidade de ouvi-lo atentamente, fazendo o exercício de não se deixar afetar pelo que já sabe de antemão sobre o assunto, impedindo, assim, que o dito não seja escutado. Os dados da pesquisa, produzidos no encontro pesquisador, interrogação e sujeitos significativos ao estudo são transformados em textos descritivos da experiência vivida e comunicada, tal como foi exposto. Assim, inicia-se a descrição fenomenológica, que tem na mira desvelar sentidos do dito, no horizonte do perguntado, quando se trata de entrevista ou depoimentos.

Ao se efetuar uma pesquisa fenomenológica, e, mais do que isso, proceder fenomenologicamente, caminha-se

1 Mundo-Vida, traduzido da palavra alemã Lebenswelt, é entendido como a realidade constituída e produzida no movimento histórico-cultural, que traz consigo o presente, o passado e o futuro em sua temporalidade. Não é um recipiente em que são colocadas as coisas e os seres mundanos, como conhecimento, teorias, etc. É o solo histórico e cultural em que habitamos (Bicudo, 2020, p. 36). 
efetuando o próprio movimento de trabalhar com sentidos e significados que não se dão sem si, mas que vão se constituindo e se mostrando em diferentes modos, "de acordo com a perspectiva do olhar e na temporalidade histórica de suas durações e respectivas expressões mediadas pela linguagem e por ela transportadas, é um grande desafio" (Bicudo, 2011, p. 41).

Consideremos uma pesquisa em que haja entrevistados, por exemplo, professores, "na entrevista do pesquisador com o sujeito significativo (entendido como aquele que vivencia o fenômeno) a pergunta disparadora age como um enredo da narrativa (descrição) realizada pelo entrevistado" (Bicudo, 2018, p.245). Com as falas transformadas em textos, o pesquisador se lança em leituras sucessivas e atentas, buscando cada vez mais se familiarizar com o que o(a) professor(a) disse, revisitando o comunicado tal como foi proferido. Como pesquisadores fenomenólogos, buscamos fazer esta leitura sem interpretação prévia, suspendendo juízos de valores, pré-conceitos e preconceitos em relação à questão inquirida pela interrogação. Nesse movimento inicial, sempre à luz da interrogação orientadora, vamos nos questionando: o que é “isso que é dito pelo sujeito?". O isso que foi dito nos diz de nossa interrogação, ou seja, como 'a responde'.

Assim procedendo, destacamos trechos dos textos descritivos significativos ao perguntado, denominando-os Unidades de Significados (US) ${ }^{2}$. Estas, por sua vez, são assim denominadas por expressarem a compreensão do pesquisador que, na dinâmica analítica, recorrentemente se questiona: 'o que isto está dizendo?', 'qual o sentido disto que está sendo dito?' São, portanto, unidades, trechos da fala dos professores, que dizem do perguntado. Trazem significados que, de certo modo, respondem ao perguntado. Trata-se, por ora, do início da análise ideográfica, que foca os discursos individualmente.

A análise ideográfica se refere ao emprego de ideogramas, ou seja, de expressões de ideias por meio de símbolos. Esse estudo penetra e enreda-se nos meandros das descrições ingênuas do sujeito, tomadas em sua individualidade. A raiz do termo está em ideografia que diz da representação das ideias por meio de símbolos gráficos. Ela revela a estrutura do discurso do sujeito, evidenciando os aspectos noemáticos da descrição (Bicudo, 2011, p.58).

A atenção do pesquisador está nas US, a fim de compreendêlas. O empenho está no exercício de articulação da linguagem, onde buscamos compreender o sentido das Unidades de Significado olhando para o todo da descrição, do vivenciado com os sujeitos significativos situados temporalmente. Não se trata apenas de destacar recortes, mas de articular ideias que possam expressar o sentido do que está sendo dito ao modo como se faz para o pesquisador.

No exercício de expressar os significados expondo sentidos que vão se fazendo, algumas pesquisas também trazem enxertos hermenêuticos para trabalhar as Unidades de Significados com vistas a anunciar como vão se constituindo falas articuladas. Alguns exemplos podem ser encontrados nos estudos de Orlovski (2014), Zontini (2014), Batista (2016), Andrade (2017), Tychanowicz (2017), Silva (2018), Mancini (2019), Melo (2019) e Pereira (2021), que no modo de proceder fenomenológico, entrevistaram professores e foram orientados no GEForProf, grupo de estudo articulado ao Grupo FEM (Fenomenologia em Educação Matemática).

Tais enxertos hermenêuticos, guiados pelos procedimentos da hermenêutica gadameriana, trazem-nos esclarecimentos, não no sentido de uma hermenêutica exegese e nem a típica de leis, embora envolva aspectos destas duas maneiras. A eles, voltamo-nos às vivências, à historicidade, aos modos como estas vivências e diálogos se mostram situados espaçotemporalmente. Muitas vezes explicitamos a pesquisa em termos do léxico, da própria fala ou expressões do entrevistado, da compreensão do pesquisador, daquilo que foi dito e como foi dito. Na hermenêutica, encontramos aberturas para compreensão.

Abertura esta em que se faz o exercício de não emitir juízos de valor para que se possa compreender, e ir compreendendo o que vem sendo dito pelos entrevistados, abrindo possibilidades ao pesquisador. Assim, recorre-se aos dicionários, ao diálogo com a literatura, e retoma-se o contexto das entrevistas em seu todo para que consigamos realizar um movimento de interpretação reflexivo. $\mathrm{O}$ enxerto hermenêutico, deste modo, mostra-se como a possibilidade de um movimento interpretativo-reflexivo não apenas técnico, embora não deixe de fora a recorrência a técnicas de interpretação linguísticas.

Assim, ao trabalharmos na dimensão da intersubjetividade, trazemos análises individuais que carregam polissemias de significados de palavras e de sentidos que avançam se articulando e expressando ideias cada vez mais abrangentes, que contribuem para compreensões que se entrelaçam.

Portanto, os procedimentos assumidos na pesquisa são inseparáveis do fenômeno focado, bem como do investigador que o interroga. Transcende a esfera da subjetividade do sujeito que põe em marcha a pesquisa, pois, de modo dialético, o movimento investigativo próprio à análise hermenêutica realiza ininterruptamente o pensar meditativo, articulando perguntas endereçadas ao texto e respostas que revelam articulações clareadoras (Mondini \& Bicudo, 2019, p. 3).

Deste modo, no destaque das Unidades de Significado, com apoio dos enxertos hermenêuticos compondo falas articuladas - expressões das compreensões do pesquisador junto ao movimento de análise -, movemo-nos, pelas reduções e convergências, para a análise nomotética.

A análise nomotética indica o movimento de reduções que transcendem o aspecto individual da análise ideográfica [...] fenomenologicamente indica a transcendência do individual

2 Conforme Bicudo (2011), Unidades de Significados são como pontos de partida das análises, quer busquem pela estrutura de um fenômeno, ou pelo dito em textos que se mostraram significativos em relação à interrogação formulada e ao fenômeno investigado. Elas se constituem em unidades que fazem sentido ao pesquisador orientado pela interrogação. 
articulada por meio de compreensões abertas pela análise ideográfica, quando devemos atentar às convergências e divergências articuladas nesse momento e avançar em direção ao seguinte, quando perseguimos grandes convergências cuja interpretação solicita insights, variação imaginativa, evidências e esforço para expressar essas articulações pela linguagem (Bicudo, 2011, p.58-59).

Da análise nomotética, explicitamos categorias abertas que expressam a estrutura do fenômeno investigado, ou seja, características nucleares. São ditas abertas porque solicitam interpretação e o pesquisador se lança nessa tarefa, no estrito diálogo com a literatura pertinente e com os depoentes pelos seus discursos.

Assim, no encontro pesquisador-interrogaçãopesquisado é que os dados são produzidos e, ao procedermos sistematicamente as análises pelas descrições da experiência vivida e comunicada, compomos sua totalidade.

Do movimento produtivo, analítico e reflexivo, reafirmamos que os dados, na pesquisa fenomenológica, não estão à disposição para serem capturados. Evitamos, assim, considerar a etapa como sendo uma coleta de dados, haja vista que estes são constituídos no movimento analítico, em que pesquisador, interrogação, pesquisado e grupo de pesquisa se lançam intencionalmente no movimento compreensivointerpretativo do proceder fenomenológico.

Tal movimento de constituição solicita o exercício metódico que requer a escuta atenta do descrito, no caso de uma entrevista com professores, uma escuta atenta do que eles dizem e como dizem no solo histórico-cultural em que se situam. Isso implica uma mudança no olhar do pesquisador, em que se diz que há uma postura, uma atitude de pesquisa que não é imposta, senão assumida por ele quando olha, ouve de modo atento e respeita o que vê. Ainda, é

[...] primordial à atitude fenomenológica o respeito, a si e ao outro. Sendo assim, o cuidado de si é importante para cuidar do outro também. Essa é uma atitude de respeito, de compreensão, de entender do que se trata isso que estamos fazendo, de entendermos o "onde" estamos (Bicudo, 2018, p. 246).

O cuidado como cura (sorge) é indicado como o processo em que o ser, que se pergunta pelo sentido de ser, articula uma compreensão de cuidado consigo, que se manifesta no cuidado com os outros, temporal e espacialmente, uma vez que somos "ser-com" ". Em outras palavras, ao cuidar do outro, também cuidamos de nós mesmos, constituindo-nos. Trata-se de uma dimensão ontológica da pessoa, o cuidado com outros e com as coisas que orientam o modo como nós nos constituímos humanos. Ou seja, o cuidado movimenta os significados que atribuímos por meio da linguagem (Heidegger, 2005).

Este cuidado no proceder metodológico é que destacamos como uma contribuição às pesquisas de formação de professores, uma vez que tal proceder abre a possibilidade de um movimento formativo cuidadoso que se desdobra em ouvir o outro numa escuta atenta. $\mathrm{O}$ pesquisador intencionalmente afasta-se de seus conceitos prévios acerca do que está sendo dito e transcrito, em busca de ouvir o outro.

A conexão do discurso com a compreensão e sua compreensibilidade torna-se clara a partir de uma possibilidade existencial inerente ao próprio discurso, qual seja a escuta. Não é por acaso que dizemos que não "compreendemos" quando não escutamos "bem". A escuta é constitutiva do discurso. E, assim como a fala está fundada no discurso, a percepção acústica também se funda na escuta. Escutar é o estar aberto existencial da presença enquanto sercom os outros (Heidegger, 2005, p. 222).

Há um cuidado enquanto abrir-se ao outro permitindo que a sua fala possa ecoar e produzir efeitos sobre o eu pesquisador com o objetivo de ultrapassar a estreiteza de seus próprios preconceitos, acolhendo a palavra do outro não como assentimento, mas como possibilidade do eu pesquisador ampliar seus modos de olhar, agir e compreender, cuidando de suas possibilidades de ser e das possibilidades de ser do outro.

\section{Conclusão}

Ao nos debruçarmos a explicitar o movimento de constituição dos dados no proceder fenomenológico em pesquisas no âmbito da formação de professores que ensinam matemática, compreendemos que tal movimento possibilita aos pesquisadores, em seu solo de pesquisa, formarem-se com seus pares num movimento contínuo e constitutivo de vir a ser, que solicita um modo ético de lidar com textos e pessoas pautados no 'cuidado'.

O 'cuidado', por sua vez, acontece dialogicamente e tem seu sentido não na certeza metodológica sobre si mesma, mas na disposição intencional que caracteriza o pesquisador face ao que pode estar preso dogmaticamente, de modo que os envolvidos se constituam singularmente na intersubjetividade junto com pares, em um contínuo vir a ser pesquisador e professor, dando-se conta do seu formar-se.

Deste modo, no proceder cuidadoso, o outro não é tratado como um objeto, mas respeitado em sua alteridade e diferença, mantendo-as intencionalmente em que ouvir o outro, no sentido de cuidar de suas possibilidades de ser, pode ser proposto e articulado como um sentido orientador nos modos de proceder sistematicamente as descrições e análises numa pesquisa de abordagem fenomenológica.

Proceder este que pode abrir mais oportunidades metodológicas às pesquisas com professores no âmbito da formação docente, favorecendo o campo de estudo da educação matemática, em que se mostra como condição de possibilidade de conhecer e produzir conhecimento de um modo coletivo e dialógico, em perspectiva e provisório.

\footnotetext{
3 Segundo Bicudo (2014), o ser-com na obra heideggeriana “diz de um modo de ser ontológico do ser do ser humano, denominado por ele de Dasein". Para a autora, com base em Heidegger, tal modo de ser do ser humano expressa que ontologicamente não há ser humano sem mundo e sem os outros. Não há possibilidade de o homem ser sem ser no mundo, revelando que o modo de ser-com se refere também aos modos como compartilha, estando no mundo com os outros. Um dos modos de ser-com é o cuidado.
} 


\section{Referências}

Andrade, S. P. (2017). Alfabetização matemática:o professor em forma-ação. Dissertação. Universidade Federal do Paraná, Setor de Ciências Exatas, Programa de Pós-Graduação em Educação em Ciências e em Matemática. Curitiba.

André, M. E. D. A. (2011). Pesquisas sobre formação de professores: tensões e perspectivas do campo. In: H. A. Fontoura, \& M., Silva. Formação de professores, culturas: desafios à Pós-graduação em Educação em suas múltiplas dimensões (pp.24-36). Rio de Janeiro: ANPEd Nacional.

Batista, J.O. Mocrosky, L.F., \& Mondini, F. (2017). Sujeito e objeto na produção do conhecimento científico. Actio, 2 (3). 44-59.

Batista, J.O. (2016). O professor que ensina matemática em ambiente tecnológico: a ead em foco. Dissertação. Universidade Federal do Paraná, Setor de Ciências Exatas, Programa de Pós-Graduação em Educação em Ciências e em Matemática. Curitiba.

Bicudo, M.A.V., \& Miarka, R. (2015). Metodologia de Pesquisa em Filosofia da Educação Matemática. Perspectivas da Educação Matemática, 8(18), 430-447.

Bicudo, M.A.V. (2010). Filosofia da Educação Matemática segundo uma perspectiva Fenomenológica. In: M. A. V. Bicudo. Filosofia da Educação Matemática: Fenomenologia, concepções, possibilidades didático-pedagógicas (pp.23-46). São Paulo: Editora UNESP.

Bicudo, M.A.V. (2011). Pesquisa qualitativa segundo a visão fenomenológica. São Paulo: Cortez.

Bicudo, M.A.V. (2014). A perplexidade: ser-com-o-computador e outras mídias. In: M.A.V. Bicudo. Ciberespaço: Possibilidades que abre ao mundo da educação (pp.37-66). São Paulo: Editora Livraria da Física.

Bicudo, M.A.V. (2020). Pesquisa Fenomenológica em Educação: Possibilidades e desafios. Revista Paradigma. doi: https://doi. org/10.37618/PARADIGMA.1011-2251. 30-56.

Bicudo, M.A.V.B. (2018). Pesquisa qualitativa e a abordagem fenomenológica: o percurso da professora pesquisadora Maria Aparecida Viggiani Bicudo. Actio, 3(3), 236-252.

Cupani, A. O. (2009). Filosofia da Ciência. Florianópolis: UFSC.

Fiorentini, D., \& Oliveira, A. (2013). O lugar da matemática na Licenciatura em Matemática: que matemáticas e que práticas formativas? Bolema, 27(47).

Fiorentini, D., Passos, C.L.B. \& Lima, R.C.R. (2016). Mapeamento da pesquisa acadêmica brasileira sobre o professor que ensina matemática: período 2001-2012. Campinas: UNICAMP.

Gatti, B.A. (2008). Análise das políticas públicas para formação continuada no Brasil, na última década. Revista Brasileira de Educação, 13(37), 57-70.

Heidegger, M. (2005). Ser e Tempo. Petrópolis:Vozes.

Husserl, E. (2002). A Crise da Humanidade Européia e a Filosofia. Porto Alegre: EDIPUCRS.

Husserl, E. (2012). A crise das ciências europeias e a fenomenologia transcendental: uma introdução à filosofia fenomenológica. Rio de Janeiro: Forense Universitária.

Imbernón, F. (2010). Formação continuada de professores. Porto Alegre: Artmed.

Mancini, L.C.M. (2019). Leituras de práticas na alfabetização matemática: um fenômeno formativo. Dissertação. Universidade Federal do Paraná, Setor de Ciências Exatas, Programa de Pós-Graduação em Educação em Ciências e em Matemática. Curitiba.

Melo, J.C. (2019). Investigação matemática pelas vozes do
PIBID/UFPR. Dissertação. Universidade Federal do Paraná, Setor de Ciências Exatas, Programa de Pós-Graduação em Educação em Ciências e em Matemática. Curitiba

Mocrosky, L.F., \& Bicudo, M.A.V. (2013). Um estudo filosófico-histórico da ciência e da tecnologia sustentando a compreensão de educação científico-tecnológica. Acta Scientiae, 15(3). 406-419.

Mocrosky, L.F. (2015). A postura fenomenológica de pesquisar em Educação Matemática In: M. A. Kalinke, \& L.F. Mocrosky. Educação matemática: pesquisas e possibilidades (pp.141-158). Curitiba: UTFPR.

Mondini, F., \& Bicudo. M.A.V. (2019). Uma interpretação analítica da organização escolar da Matemática durante a Primeira República Brasileira. Zetetiké, 27. 1-25.

Mondini, F., Paulo, R.M., \& Mocrosky, L.F. (2018). As contribuições da Fenomenologia à Educação. Anais do V Seminário Internacional de Pesquisa e Estudos Qualitativos, Foz do Iguaçu, PR, Brasil, 1.

Moura, C.A.R. (1989). Crítica da razão na fenomenologia. São Paulo: Nova Stela.

Nacarato, A.M., \& Grando, R.C. (2015). A Pesquisa com e pelas Professoras que Ensinam Matemática. Anais do VI Seminário Internacional de Pesquisa em Educação Matemática, Pirenópolis, GO, Brasil.

Nacarato, A.M. (2005). A escola como lócus de formação e de aprendizagem: possibilidades e riscos da colaboração. In: D. Fiorentini, \& A.M. Nacarato. Cultura, formação e desenvolvimento profissional de professores que ensinam matemática: investigando e teorizando a partir de prática (pp 175-195). São Paulo: Musa.

Orlovski, N. (2014). A forma-ação do professor que ensina matemática nos anos iniciais. Dissertação. Universidade Federal do Paraná, Setor de Ciências Exatas, Programa de Pós-Graduação em Educação em Ciências e em Matemática. Curitiba.

Pereira. E. P. (2021). O ensino da matemática com tecnologias digitais: compreensões de professores atuantes na Educação Básica. Dissertação. Universidade Federal do Paraná, Setor de Ciências Exatas, Programa de Pós-Graduação em Educação em Ciências e em Matemática. Curitiba, PR, Brasil.

Ponte, J.P. (2002). Investigar a nossa própria prática. In: GTI. Reflectir e investigar sobre a prática profissional (pp. 5-28). Lisboa: APM.

Ponte, J.P. (2012). Estudiando el conocimiento y el desarrollo profesional del profesorado de matemáticas. En: N., Planas. Teoría, crítica y práctica de la educación matemática (pp. 8398). Barcelona: Graó.

Silva, D.C.G. (2018). Desafios de ensinar matemática na educação básica: um estudo com professores no início de carreira. Dissertação. Universidade Federal do Paraná, Setor de Ciências Exatas, Programa de Pós-Graduação em Educação em Ciências e em Matemática. Curitiba.

Tychanowicz, S.D. (2017). O ensino da divisão nos anos iniciais: compreensões dialogadas. dissertação. Universidade Federal do Paraná, Setor de Ciências Exatas, Programa de PósGraduação em Educação em Ciências e em Matemática. Curitiba, PR, Brasil.

Zontini, L.R.S. (2014). O Pró-Letramento em Matemática: compreensões do professor-tutor sobre ideias que sustentam o ensino da matemática nos anos iniciais. Dissertação. Universidade Federal do Paraná, Setor de Ciências Exatas, Programa de Pós-Graduação em Educação em Ciências e em Matemática. Curitiba. 